\title{
PORNO DE VINGANÇA: REVISÃO SISTEMÁTICA DO SISTEMA JURÍDICO BRASILEIRO
}

\author{
REVENGE PORN: SYSTEMATIC REVIEW OF THE BRAZILIAN LEGAL SYSTEM
}

\author{
Adriana Moreira Dias ${ }^{1}$ \\ Eduardo Nathan Cordeiro Borges ${ }^{2}$ \\ Zilmária Aires dos Santos ${ }^{3}$
}

\section{RESUMO}

Com a evolução da utilização da internet nos últimos tempos, é possível além de proporcionar interação interpessoal, trabalhar, ensinar, realizar transações comerciais ou financeiras. Novas vertentes por mais que com a intenção de "conexão", muitas vezes, acabam por ser comprometidas pelo mau uso das tecnologias. O que vem preocupando as autoridades e os usuários é a dificuldade de alcance do sistema jurídico do Estado e bem como a dificuldade de punição. Nesse cenário, esse artigo tem por objetivo esclarecer ao leitor sobre os crimes cibernéticos, suas consequências e mais especificamente o tema revenge porn que trata-se de um crime sofrido por mulheres no crivo íntimo e virtual. A metodologia utilizada foi a revisão sistemática de literatura com base no método hipotético-dedutivo, a definição de dimensões foram construídas com base em observações colhidas sistematicamente e complementadas com informações isoladas pelo método empírico. Os resultados com base nos indicadores utilizados apontam que o ordenamento jurídico age desde o ano de 2012 de forma cautelosa na tentativa de impedir a divulgação íntima de imagens sem o consentimento das vítimas, entretanto somente recentemente conceituou-se o crime no

\footnotetext{
${ }^{1}$ Acadêmica do curso de Direito da Universidade Estadual do Tocantins (Unitins), Campus Dianópolis/TO, E-mail: adrianamoreiradias@gmail.com ORCID https://orcid.org/00000002-7342-6729

${ }^{2}$ Acadêmico do curso de Direito da Universidade Estadual do Tocantins (Unitins), Campus Dianópolis/TO, E-mail: eduardocordeiroborges@gmail.com ORCID https://orcid.org/0000-0001-6641-3113

3 Mestra em Prestação Jurisdicional e Direitos Humanos pela Universidade Federal do Tocantins (UFT/ESMAT). Especialista em Direito Civil e Direito Processual Civil pela Faculdade Vale do Rio Doce de Governador Valadares/MG. Especialista em Gestão do Judiciário pela Faculdade Educacional da Lapa (Fael). Bacharel em Direito pela Universidade de Gurupi-TO (Unirg). Professora do curso de Direito da Universidade Estadual (UNITINS), Campus Dianópolis-TOE-mail: zilmaria.as@unitins.br ORCID https://orcid.org/0000-0002-1670-4171
} 
Código Penal e por mais que o desejo social seja uma legislação mais incisiva percebese uma grande discussão no âmbito legislativo e uma cautela na criação de leis que sejam tipicamente reconhecidas pelo sistema jurídico nacional. Aborda-se ainda, a importância de grupos de combate aos crimes virtuais, além de sugerir maior disseminação de conhecimentos sobre penalidade, meios e formas de denuncia aos crimes de pornografia de vingança.

PALAVRAS-CHAVE: pornô de vingança, leis, marco civil da internet.

\section{ABSTRACT}

With the evolution of use the internet, it is possible as well as providing interpersonal interaction, work, teach, make commercial or financial transactions. New strands no matter how much with the will of "connection", often end up being compromised by the misuse of technologies. What has been worrying authorities and users is the difficulty of reaching the state's legal system and the difficulty of punishment. In this scenario, this article aims to clarify to the reader about cyber-crimes, their consequences and more specifically the theme revenge porn, which is a crime suffered by women in the intimate and virtual environment. The methodology used was the systematic literature review based on the hypothetical-deductive method, the definition of dimensions were constructed based on observations collected systematically and complemented with isolated information by the empirical method. The results based on the used indicators indicates that the legal system has acted since 2012 in a cautious way in an attempt to prevent the intimate dissemination of images without the victims' consent, however only recently was created in the Penal Code and as much as the social desire is a more incisive legislation, there is a great discussion in the legislative ambit and a caution in the creation of laws that are typically recognized by the national legal system. It also discusses the importance of groups for combating cyber-crime, in addition to suggesting greater dissemination of knowledge on penalties, means and ways to report crimes of revenge pornography.

KEYWORDS: Revenge porn, laws, civil framework of the internet.

\section{INTRODUÇÃO}

A internet surgiu após a guerra fria foi de forma ampla e quase que unicamente desenvolvida pelos Estados Unidos, inicialmente com o objetivo militar como forma de controle de uma superpotência hegemônica, mas que com o passar dos anos deixou de ser unicamente militar e passou a ter abertura para as relações humanas sociais e que 
atualmente é quase que impossível de se manter a distância desta forma tecnológica de interseção. (ROCHA, SOUZA FILHO, 2016, p. 03).

$O$ acesso à internet no mundo moderno provém de um avanço ao campo de transmissão e acesso ao conhecimento na evolutiva do homem. Embora o campo de sua evolução seja muitas vezes inseguro e o mesmo encontre dificuldade de se antecipar aos riscos advindos de suas atividades na rede tanto de forma individual como coletiva (MARRA, 2019, p. 02).

Por mais que o desenvolvimento tecnológico tenha proporcionado um avanço significativo nas relações sociais e integração dos usuários das redes, o acesso livre a internet causa uma falsa sensação de "campo de livre atuação" ou até mesmo "terra sem lei" para o usuário. E até mesmo por ser um campo de difícil delimitação de território, visto que um acesso no Brasil possa alcançar o exterior em segundos, a legislação brasileira tentou adotar mecanismos de controle dos crimes que venham a ocorrer em seu território por meio da Lei 12.965/2014 conhecida popularmente como Lei do Marco Civil da Internet.

A lei do Marco Civil da Internet surgiu como forma de impor limites para essas falsas ideias de que a internet é uma terra sem lei, para isso desde o ano de 2000 diversos projetos de leis foram apresentados ao Congresso Nacional, mas somente no ano de 2011 foi apresentado como projeto de Lei o 2.126/2011 e posteriormente aprovada no ano de 2014 a Lei 12.965/2014 (SOUZA FILHO, 2016, p. 273).

Inegável o avança legislativo, contudo os crimes cibernéticos já vinham sendo denunciados antes da edição da citada lei. Alguns crimes quando praticados por meio de uso da internet, os também chamados de projeção atípica da norma, não estão previstas expressamente no Código Penal Brasileiro, pelo fato de sua edição ter ocorrido em 1.940, merecendo que as leis especiais os definam com mais especificação evitando-se aplicações de sanções que possam ferir a própria Constituição Federal de 1.988.

O mundo moderno impõe aos cidadãos o uso de ferramentas que possam auxiliar nas atividades diárias. A conectividade via internet, por meio de diversos dispositivos, é realidade de boa parte da população mundial e o uso de telefones smartphones tornou mais acessível à comunicação via aplicativos quase que de forma 
instantânea e apesar dos benefícios da tecnologia, é inegável que muitos não a utilizam de forma responsável.

Nesse sentido, o presente trabalho busca identificar o crime cibernético conhecido como pornografia de vingança, que trata da divulgação indevida de imagens íntimas como forma de exposição negativa da vítima geralmente após o fim do relacionamento, dos quais $81 \%$ dos crimes de revenge porn são sofridos por mulheres, sendo que, entre as vítimas, de 1 entre 4 são adolescentes, conforme informações da ONG SaferNet (VARELLA; SOPRANA. 2016, s/p.).

Questiona-se se atualmente a legislação é efetiva ao punir crimes de revenge porn, e qual seria a melhor forma de garantir que não exista a impunidade ao usuário que atuar de forma anônima nas redes, vez que tem se tornado prática comum a exposição de fotos íntimas de mulheres anônimas em grupos de WhatsApp, tanto que a ação passou a ser tipificada como crime, quando da alteração ao Código Penal Brasileiro (1.940) por meio da Lei no13.718/2018 que incluiu o art. 218-C ao referido Código.

Buscou-se neste artigo estudar o crime de revenge porn e a atuação do sistema jurídico brasileiro e com isso uma construção seletiva dos conceitos jurídicos da pornografia de revanche e descrição da atuação do Estado na prevenção e punição nos casos após a publicação da Lei do Marco Civil da Internet especificamente no espaço amostral do ano de 2019.

\section{MATERIAL E MÉTODO}

Para Lakatos e Marconi (2003, p.84/85) "Os artigos científicos são, porém completos que tratam de uma questão verdadeiramente científica [...] Esse tipo de trabalho proporciona não só a ampliação de conhecimentos como também a compreensão de certos assuntos. [...]" desta maneira o presente trabalho dedica a produção de artigo por meio de estudos que proporcionem a compreensão do assunto revenge porn.

Severino (2017, p.50/64) aponta diretrizes de leitura para análise e interpretação de textos, o presente trabalho pauta-se na análise interpretativa tomando como base as leituras feitas de forma dinâmica localizou-se objetivamente a ideia central dos autores. 
E a partir de opiniões diversas construiu-se um conceito próprio do objeto de estudo, "dialogando com os autores" transformou-se em uma base para construção própria de conceitos sobre o assunto.

Foi realizada uma pesquisa sistemática em artigos científicos e monografias do ano de 2019, com as seguintes palavras chave: Lei do Marco Civil da Internet; Mulher; e Revenge Porn. Estas palavras se relacionam uma vez que há um interesse de se investigar como o sistema jurídico brasileiro recepcionou a Lei 12.965/2014 e como vem atuando nos casos de revenge porn.

A plataforma escolhida para análise de conteúdo foi por meio do Google Scholar, disponível em: https://scholar.google.com.br/scholar?q=, onde foram encontrados respectivamente: 06 artigos; 03 dissertações; 11 Monografias; e 01 tese, todas publicadas no ano de 2019, buscando-se as que tivessem em seu contexto as palavras chaves: Lei do Marco Civil da Internet; Mulher; e Revenge Porn.

Os trabalhos encontrados foram analisados da seguinte forma: Leitura sistematizada, que resultou em um resumo dos trabalhos que foram destinados para atender a pesquisa para a produção do estudo.

Por meio da pesquisa exploratória com a intenção de conceitualização do crime revenge porn baseando-se em estudos do ano de 2019 sobre o tema e com suporte no levantamento de demandas a pesquisa buscou um entendimento conclusivo do sistema jurídico com base nesta modalidade de crime virtual.

Evidenciam Quivy \& Campenhoudt (1995, p. 149): de que a "conceitualização, ou a construção de conceitos, constitui uma construção abstrata", mas que passa a empenhar-se da realidade. Para tanto, "ela não dá conta de todas as dimensões e aspectos do real, mas somente o que expressa o essencial segundo o ponto de vista do pesquisador".

\section{RESULTADO}

A pesquisa contou com um universo de 21 trabalhos para serem analisados, descartou-se um total de 09 trabalhos por não terem relação direta com o tema de estudo, sendo assim, listaram-se 12 (doze) artigos analisados com uma breve síntese 
do trabalho. Abaixo é possível observar uma relação direta com o estudo, os trabalhos selecionados:

Quadro 1 - Trabalhos selecionados/objeto da pesquisa

\begin{tabular}{|c|c|c|c|}
\hline TEMA & $\begin{array}{l}\text { DATA } \\
\text { PUBLICAÇÃO }\end{array}$ & AUTOR & LINK \\
\hline $\begin{array}{l}\text { Responsabilidade penal do } \\
\text { agente diante da pornografia não } \\
\text { consensual perante os crimes } \\
\text { cibernéticos contra a mulher no } \\
\text { ordenamento jurídico brasileiro }\end{array}$ & 06/11/2019 & $\begin{array}{l}\text { Aline Isadora } \\
\text { Costa } \\
\text { Cantuária } \\
\text { e } \\
\text { Joyce Lobato } \\
\text { Novais }\end{array}$ & $\begin{array}{l}\text { http://periodicos.ceap.br/in } \\
\text { dex.php/rcmc/article/view/ } \\
\text { 25/17. v. } 1 \text { n. } 1 \text { (2019): } \\
\text { REVISTA CIENTÍFICA } \\
\text { MULTIDISCIPLINAR DO } \\
\text { CEAP }\end{array}$ \\
\hline $\begin{array}{l}\text { PORNOGRAFIA DE VINGANÇA: } \\
\text { Violência de gênero na internet e } \\
\text { tutela da intimidade sexual - um } \\
\text { estudo comparado (itália e brasil) }\end{array}$ & $30 / 11 / 2019$ & $\begin{array}{l}\text { Kauane } \\
\text { Fiorio } \\
\text { e } \\
\text { Margareth } \\
\text { Vetis } \\
\text { Zaganelli }\end{array}$ & $\begin{array}{l}\text { www.derechoycambiosoci } \\
\text { al.com | ISSN: } 2224-4131 \\
\text { | Depósito legal: 2005- } \\
5822198 \text { N. }{ }^{5} \text { 59, ENE- } \\
\text { MAR } 2020\end{array}$ \\
\hline $\begin{array}{l}\text { O REVENGE PORN NO BRASIL } \\
\text { E AS CONSEQUENNCIAS DA } \\
\text { CRIMINALIDADE DIGITAL PARA } \\
\text { OS DIREITOS HUMANOS DE } \\
\text { CRIANÇAS E ADOLESCENTES: } \\
\text { uma análise a partir das decisões } \\
\text { do superior tribunal de justiça }\end{array}$ & 28/08/2017 & $\begin{array}{l}\text { Felipe da } \\
\text { Veiga Dias } \\
\text { e } \\
\text { luri Bolesina }\end{array}$ & $\begin{array}{l}\text { Editora Unijuí • ISSN } \\
2179-1309 \text { Ano } 7 \cdot n^{\circ} 14 \cdot \\
\text { Jul./Dez. } 2019 \cdot \text { Qualis B1 }\end{array}$ \\
\hline $\begin{array}{l}\text { Pornografia de vingança e a } \\
\text { tutela dos direitos fundamentais } \\
\text { da vítima }\end{array}$ & 03/04/2019 & $\begin{array}{l}\text { Diego Sígoli } \\
\text { Domingues }\end{array}$ & $\begin{array}{l}\text { http://bibliotecatede.unino } \\
\text { ve.br/handle/tede/2115 }\end{array}$ \\
\hline $\begin{array}{l}\text { CRIMES VIRTUAIS E NOVAS } \\
\text { MODALIDADES DE VIOLÊNCIA } \\
\text { DE GÊNERO CONTRA A } \\
\text { MULHER: a divulgação não } \\
\text { consentida de imagens íntimas na } \\
\text { internet }\end{array}$ & 2019 & $\begin{array}{l}\text { Ana Larissa } \\
\text { Gonçalves } \\
\text { Guimarães }\end{array}$ & $\begin{array}{l}\text { http://www.repositorio.ufc. } \\
\text { br/handle/riufc/49210 }\end{array}$ \\
\hline $\begin{array}{l}\text { PRIVACIDADE NA ERA } \\
\text { DIGITAL: a intimidade na rede e a } \\
\text { suposta misoginia na } \\
\text { interpretação dos magistrados }\end{array}$ & $06 / 2019$ & Daiane Gross & $\begin{array}{l}\text { http://hdl.handle.net/1073 } \\
7 / 2577\end{array}$ \\
\hline $\begin{array}{l}\text { BIOPODER E DESIGUALDADE } \\
\text { DE GÊNERO: } \\
\text { A sujeição do corpo feminino }\end{array}$ & 2019 & $\begin{array}{l}\text { Vívian Maria } \\
\text { Segato }\end{array}$ & $\begin{array}{l}\text { http://intertemas.toledopru } \\
\text { dente.edu.br/index.php/Dir } \\
\text { eito/article/view/7706/676 } \\
48285\end{array}$ \\
\hline
\end{tabular}




\begin{tabular}{|l|l|l|l|}
\hline $\begin{array}{l}\text { A pornografia de vingança como } \\
\text { violência de gênero e a ineficácia } \\
\text { da pena mínima abstrata }\end{array}$ & 2019 & $\begin{array}{l}\text { Tauane Paes } \\
\text { Landim Alves }\end{array}$ & $\begin{array}{l}\text { https://repositorio.uniceub. } \\
\text { br/jspui/handle/prefix/1380 } \\
9\end{array}$ \\
\hline $\begin{array}{l}\text { A APLICABILIDADE DA JUSTIÇA } \\
\text { RESTAURATIVA AOS CASOS } \\
\text { DE PORNOGRAFIA DE } \\
\text { VINGANÇA: um olhar às } \\
\text { necessidades das vítimas }\end{array}$ & 2019 & $\begin{array}{l}\text { Edna Vitoreti } \\
\text { Corrêa }\end{array}$ & $\begin{array}{l}\text { http://www.riuni.unisul.br/h } \\
\text { andle/12345/7480 }\end{array}$ \\
\hline $\begin{array}{l}\text { CRIMES VIRTUAIS: } \\
\text { possibilidades e limites da sua } \\
\text { regulamentação no brasil }\end{array}$ & $21 / 06 / 2019$ & $\begin{array}{l}\text { Sâmya } \\
\text { Pereira } \\
\text { Meneses }\end{array}$ & $\begin{array}{l}\text { http://repositorio.unifametr } \\
\text { o.edu.br/jspui/handle/1234 } \\
56789 / 107\end{array}$ \\
$\begin{array}{l}\text { A VIOLÊNCIA DE GÊNERO DA } \\
\text { PORNOGRAFIA DE VINGANÇA } \\
\text { EM APLICATIVOS DE } \\
\text { MENSAGENS INSTANTÂNEAS: } \\
\begin{array}{l}\text { Uma análise jurisprudencial do } \\
\text { Superior Tribunal de Justiça }\end{array}\end{array}$ & 2019 & $\begin{array}{l}\text { Raíssa de } \\
\text { Almeida } \\
\text { Lopes }\end{array}$ & $\begin{array}{l}\text { https://repositorio.uniceub. } \\
\text { br/jspui/handle/prefix/1332 } \\
1\end{array}$ \\
\hline $\begin{array}{l}\text { Pornografia de vingança e a } \\
\text { indenização no direito civil } \\
\text { brasileiro }\end{array}$ & $27 / 06 / 2019$ & $\begin{array}{l}\text { Julia Pereira } \\
\text { de Oliveira }\end{array}$ & $\begin{array}{l}\text { http://www.riuni.unisul.br/h } \\
\text { andle/12345/7618 }\end{array}$ \\
\hline
\end{tabular}

Fonte: Elaborado pelos autores com base nos trabalhos científicos selecionados, 2020.

O sistema jurídico brasileiro, no que tange ao revenge porn e a recepção da Lei 12.965/2014 considera-se os seguintes resultados explicitados como uma síntese de pesquisas na área das ciências jurídicas em atenção ao crime virtual supracitado.

O primeiro levantamento a ser demonstrado graficamente são as terminologias adotadas para crimes virtuais, que foram consideradas importantes para os autores antes de adentrar as características do sistema jurídico e de como ele aborda os crimes virtuais em específico o de pornografia de revanche. 
Gráfico 1 - Percentual de terminologias utilizadas nas obras

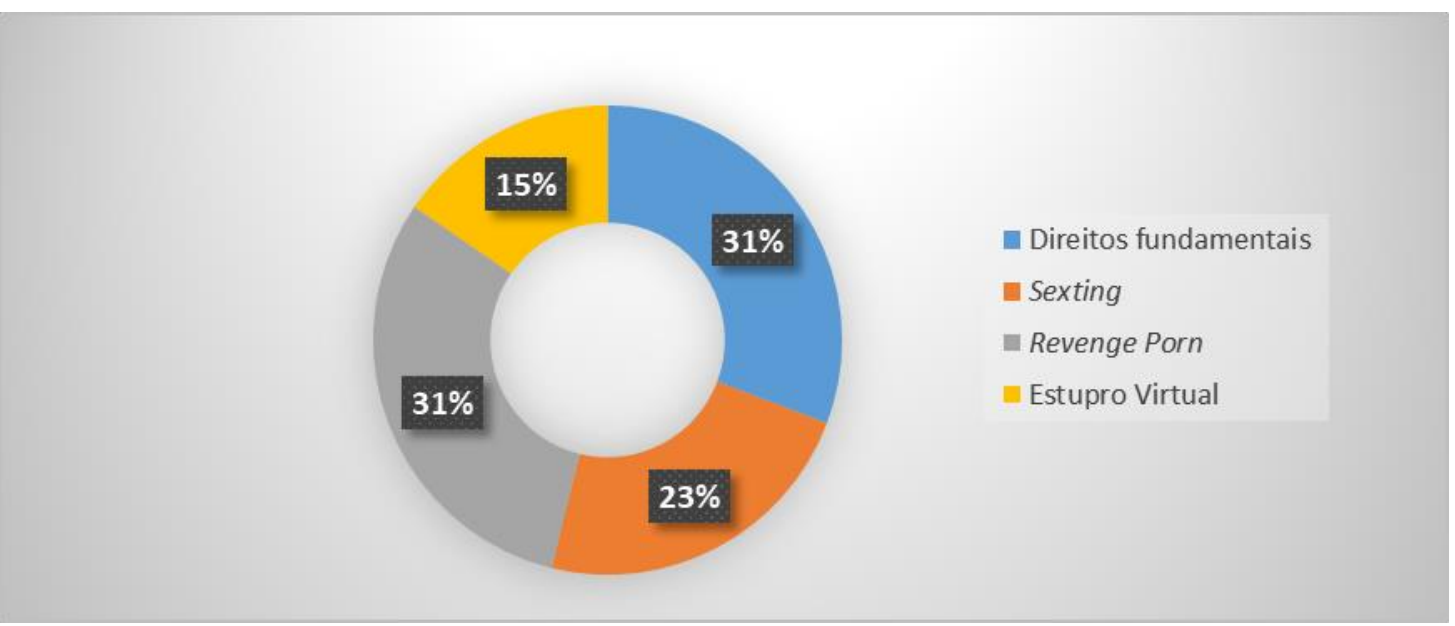

Fonte: Elaborado pelos autores com base nos trabalhos selecionados/Quadro - 01, 2020.

Como se pode observar parte-se de uma correlação entre direitos fundamentais aos crimes de revenge porn, em um breve histórico ressalta-se a universalidade dos direitos fundamentais por destinarem-se a todos sem qualquer distinção (DOMINGUES, 2019, p.13).

Além desses direitos constitucionalizados aborda-se "novos" termos que conceituam os crimes virtuais e com base no espaço amostral escolhido são termos mais utilizados o "sexting" e "revenge porn", que respectivamente trata-se: do fornecimento de imagens íntimas de cunho sexual por livre consentimento, mas que não é considerado um abuso ou ilegalidade, considerando-se uma dinâmica amorosasexual.

Já a pornografia de vingança ou revenge porn é o abuso do fornecimento consentido de imagens quando o indivíduo compartilha as imagens sem o aval de uso da sua imagem o que de forma enraizada é cometido como forma de vingança em sua maioria por homens pelo fim do relacionamento com a vítima (FLACH, 2019, p.03).

Fiorio e Zaganelli (2020, p.04/15), fazem uma reflexão acerca do termo "pornografia de vingança" devido a sua associação à índole moral da vítima (o termo pornografia remetendo a obscenidade moral), fazendo um aporte de que a conduta da mulher confere ao autor o direito de divulgar as imagens. Identifica-se o preconceito empregado pela terminologia sugere-se que o termo correto seria o termo "non 
consensual intimate images" (disseminação não consensual de imagens íntimas DNCII).

Visando proteger a mulher na sua vida privada e também a sua intimidade foram editadas e promulgadas leis, decretos - leis os quais conceituam e tipificam condutas violadoras de direitos individuais da mulher. Desde a Lei 12.737/2012 (Lei Carolina Dieckman) o sistema jurídico adotou medidas que visam amparar essas novas modalidades de crimes no ambiente virtual, as alterações do Código Penal Brasileiro (1.940) demonstram como hodiernamente antes mesmo do Marco Civil o legislador buscava medidas de proteção para vítimas de crime virtual.

Abaixo gráfico sobre a linha do tempo de alterações legislativas mais citadas pelos autores dos trabalhos analisados.

Gráfico 2 - Evolução jurídica no Brasil.

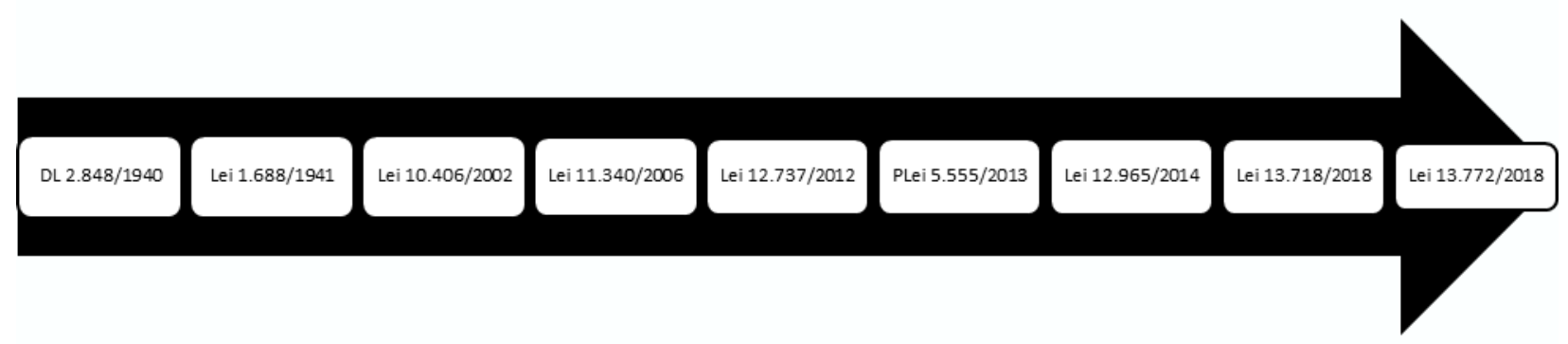

Fonte: Elaborado pelos autores com base na /Quadro - 01, 2020.

Toda a legislação vigente que visa o combate aos crimes virtuais, em especial a proteção de mulheres nos casos de revenge porn, muito além que um Marco Civil da Internet (alusão à lei 12.965/2014) trata-se de um marco regulatório eminente, que em pouco mais de dois anos provocou uma mudança significativa no ordenamento jurídico brasileiro, vislumbrando-se preocupação e a intenção do legislador é garantir a efetividade dos direitos individuais e a proteção da intimidade. (GROSS, 2019, p. 13). 
Dentre as leis abordadas, criando-se uma linha do tempo da evolução jurídica dos crimes virtuais citou-se o Código Penal Brasileiro (1.940) que sofreu alterações recentes como, por exemplo, a alteração dada pela Lei ํㅜ 12.737/2012 conhecida como Lei Carolina Dieckman que inseriu no seu bojo o art. 154-A, o caso de repercussão nacional representou alteração significativa na legislação sobre crimes virtuais e podese considerá-la pioneira no assunto, em resumo, a lei penaliza condutas relacionadas à invasão de dispositivos informáticos sem permissão.

Ainda com relação à Lei № 12.737/2012, conhecida como lei Carolina Dieckman, e a Lei no 12.965/2014, conhecida como Lei do Marco Civil da Internet, pondere-se que proponham princípios norteadores do uso da tecnologia e dos provedores de internet que são instrumento para auxiliar nas investigações da polícia civil e do Ministério Público nos casos de pornografia de vingança. Sobre isso vejamos o que escreveu Alves (2019, p. 32).

[...] os provedores de aplicações de internet devem manter, em ambiente controlado e seguro, pelo prazo de 06 meses, todos os registros de acesso, ou seja, essa disposição consiste na obrigação que os sítios possuem de manter guardadas todas as informações sobre os conteúdos gerados pelos usuários da rede (ALVES, 2019, p. 32).

A justificativa para essa obrigação decorre da necessidade dos órgãos estatais de acessar esses conteúdos para investigar condutas criminosas no meio cibernético.

O autor acrescenta, que no caso da pornografia de vingança, por exemplo, essa disposição possui um significado especial, pois é através dela que a Polícia Civil e o Ministério Público conseguem identificar os autores das condutas e, assim, buscar a sua punição (ALVES, 2019, p. 32).

Outra alteração significativa no Código Penal Brasileiro (1.940) foi a Lei № 13.718/2018, que passou a criminalizar a divulgação de cenas de estupro, de estupro de vulnerável, de sexo e de pornografia. Nesses casos a pena é de 1 a 5 anos de reclusão se o fato não for grave, aumentada em 1/3 (um terço) a 2/3 (dois terços) se 0 crime for praticado por agente que mantém ou tenha mantido relação íntima de afeto com a vítima ou que tenha como finalidade a vingança ou a humilhação. 
Ressalte-se que após a publicação da Lei o 13.772/2018, que alterou a Lei 11.340/2006, conhecida como lei Maria da Penha, a violação da intimidade da mulher passou a ser considerada violência de gênero, no contexto da violência doméstica.

O Código Civil (2.002), Lei 10.406/2002, seguindo o que preconiza a Constituição da República Federativa do Brasil (1.988), quanto à proteção dos direitos individuais, aborda inúmeras violações passíveis de indenização, como: o direito a imagem, à privacidade, à integridade física e psíquica e a honra (OLIVEIRA, 2019, p. 38/51).

$\mathrm{Na}$ mesma toada, a Lei 11.340/2006, visa proteger especificamente mulheres contra violência doméstica, entretanto deve-se ter em perspectiva que o crime de pornografia de vingança é uma violência de gênero acentuada pela modernização da prática criminosa, baseando-se em valores sexistas que utilizam de um ambiente virtual, mas que mantem a premissa de ataque à liberdade e a integridade física e moral da mulher (GUIMARÃES, 2019, p. 32/35).

Quanto aos mecanismos sociais disponíveis para auxiliar a mulheres vítimas, importante frisar que além do Poder Judiciário, Ministério público e as polícias militar e civil e Ministério da Mulher, o Brasil conta com o trabalho de ONG's - Organizações não governamentais que tem desempenhado papel importantíssimo no combate, proteção e auxílio das mulheres vítimas.

Abaixo percentual de atendimentos realizados por Ong's citadas nos trabalhos analisados.

Gráfico 3 - Porcentagem de ONG's e canais de auxílio às vitimas

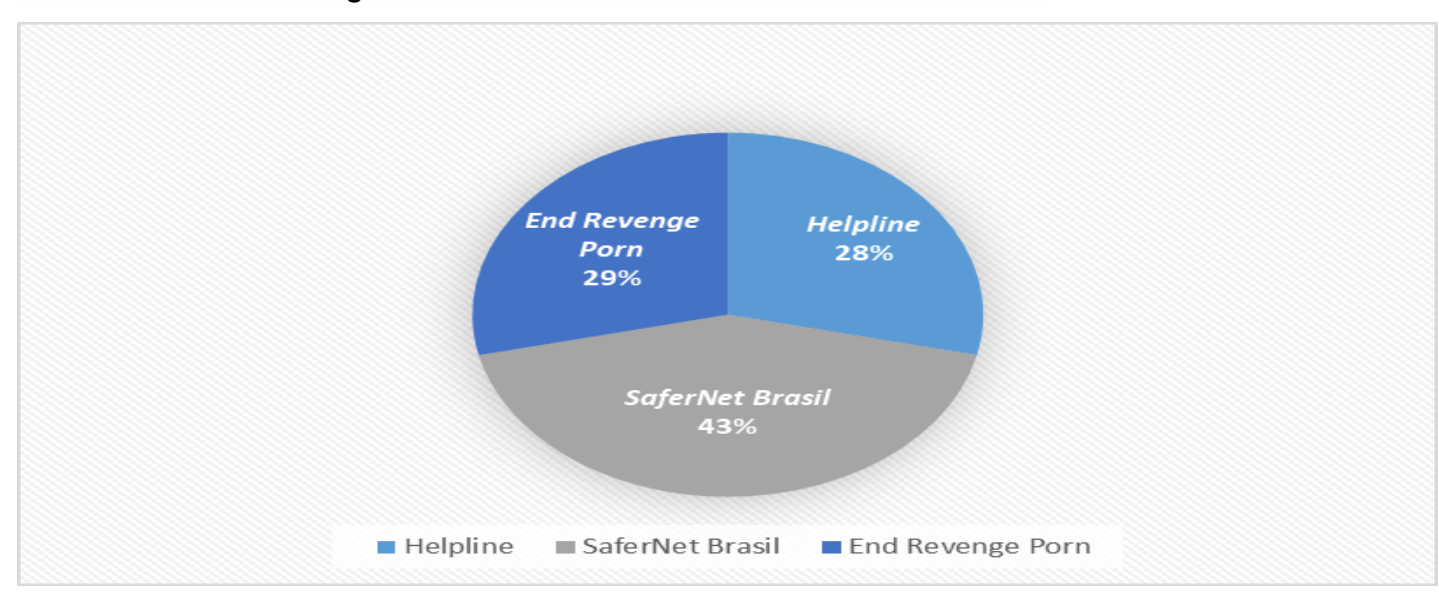

Fonte: Elaborado pelos autores com base nos trabalhos analisados/Quadro - 01, 2020. 
Entre outros mecanismos, e de acordo com Alves (2019, p. 57), as ONGs tem se mostrado como uma boa alternativa para realizar levantamentos dos crimes virtuais de revenge porn, vez que criam canais de comunicação de crimes e auxiliam na retirada de conteúdos íntimos divulgados sem autorização.

Em 43\% dos trabalhos analisados citou-se a equipe da ong SaferNet Brasil, uma associação que demonstra os crimes mais praticados na internet e as principais vítimas desses crimes, tendo criado o canal Helpline de atendimento aos usuários "onde as vítimas de crimes digitais podem requerer o auxílio da equipe da referida organização.

Outra organização não governamental que merece destaque é a ONG End Revenge Porn que, segundo Domingues (2019, p. 63) tem como objetivo institucional auxiliar as vítimas na proteção dos seus direitos civis na rede mundial de computadores.

\section{CONCLUSÃO}

O acesso à internet garante conexão com outra realidade "mundo virtual" que ocupa espaço com o mundo real, um local por muitos considerado com o "ambiente sem lei", mas que ao contrário do que se acredita vem sido amplamente discutido no poder legislativo.

A discussão sobre os crimes virtuais em relação às mulheres foi instituído pela Lei Carolina Dieckman, uma mulher que sofreu exposição da intimidade por motivo de chantagem, entretanto o que este trabalho vislumbra são os casos em que houve a exposição da vítima por vingança apenas como forma de manchar a honra da mulher.

Faz-se associação do crime de revenge porn quanto a violência doméstica contra a mulher, que por meio da conhecida lei Maria da Penha, visa proteger as mulheres de crimes físicos e psicológicos, sendo assim percebe-se que há relação, pois o intuito do ofensor/agressor virtual é especificamente atingir psicologicamente a vítima tratando-se assim de um crime de violência doméstica, cujo alvo é o abalo moral e psíquico.

Segundo Silva e Marques (2019, p.25/27) os crimes praticados na internet são chamados de ações projecionais atípicas, por não estarem a termo escritas no Código 
Penal Brasileiro (1.940). Antes da Lei $13.718 / 2018$ as condutas de revenge porn eram punidas com base nos artigos 138, 139 e 140 do referido Código Penal, crimes contra a honra que sujeitava a vítima à desistência da ação penal e resultando em diversas retratações.

Após a aprovação da Lei 13.718/2018 houve uma mudança significativa no ordenamento, o reconhecimento no Código Penal Brasileiro em vigor, na proteção de mulheres e crianças que contém normas específicas, mas que necessitavam de um aparato de maior rigidez que puna os criminosos virtuais. Não há efetividade defensável pelos pesquisadores estudados, mas pode-se inferir que exista uma rede de proteção a esses direitos que estão constantemente sendo pautada em projetos de leis.

Entende-se que o Poder Legislativo brasileiro tem conhecimento da necessidade de se acompanhar os crimes virtuais por se tratar de uma dimensão que muda constantemente e evolui de uma forma prejudicial aos grupos mais vulneráveis como as mulheres.

Importante avanço legislativo foi a edição e promulgação da Lei do Marco Civil da Internet delimitou as fronteiras de responsabilidade em relação aos provedores, dando capacidade ao legislador de delimitar espaços mais estreitos e específicos como no caso de pornografia de vingança, a interdição de conteúdos impróprios divulgados e facilitando as investigações nos casos de criminosos anônimos por meio de acesso aos bancos de dados em servidores por período previsto em lei.

Cabe salientar que existem diversos conflitos existentes que devem ainda ser discutidos para melhorar a punição e efetividade das normas em relação ao revenge porn, e mais, sugere-se que no intuito de compreensão do assunto que se invista em uma educação digital dos usuários e assim passa-se à uma nova curva de estudo de acordo com a reação da sociedade.

\section{REFERÊNCIAS}

ALVES, Tauane Paes Landim. A pornografia de vingança como violência de gênero e a ineficácia da pena mínima abstrata. Monografia (Graduação de Direito) -

Faculdade de Ciências Jurídicas e Sociais - FAJS, do Centro Universitário de Brasília UniCEUB, Brasília, Brasília, 2019. 
BRASIL. Decreto-Lei o 2.848 de 07 de dezembro de 1.940. Institui o Código Penal. In: Diário da Republica Federativa do Brasil. Rio de Janeiro, 31 dez. 1.940. Disponível em: http://www.planalto.gov.br/ccivil_03/decreto-lei/del2848compilado.htm. Acesso em: 25 jan. 2020.

. Lei no 10.406 de 10 de janeiro de 2002. Institui o Código Civil Brasileiro (2002). Diário Oficial da República Federativa do Brasil. Brasília, 11 jan. 2020. Disponível em: http://www.planalto.gov.br/ccivil_03/_ato2015-2018/2018/lei/L13718.htm. Acesso em 23 jan. 2020.

. Lei 12.965 de 23 de abril de 2014. Estabelece princípios, garantias, direitos e deveres para o uso da Internet no Brasil. In: Diário da República Federativa do Brasil. Brasília, 24 abr. 2014. Disponível em: http://www.planalto.gov.br/ccivil_03/_ato2011-2014/2014/lei//12965.htm. Acesso em: jan. 2020.

. Lei oㅜ 13.718, de 24 de setembro de 2018. Altera o Decreto-Lei no 2.848, de 7 de dezembro de 1.940 (Código Penal), para tipificar os crimes de importunação sexual e de divulgação de cena de estupro, tornar pública incondicionada a natureza da ação penal dos crimes contra a liberdade sexual e dos crimes sexuais contra vulnerável, estabelecer causas de aumento de pena para esses crimes e definir como causas de aumento de pena o estupro coletivo e o estupro corretivo; e revoga dispositivo do Decreto-Lei no 3.688, de 3 de outubro de 1941 (Lei das Contravenções Penais). In: Câmara legislativa. Brasília, 25 de nov. 2018. Diário Oficial da União - Seção 1 - 25/9/2018, Página 2.

. Lei no 12.737 , de 30 de novembro de 2012. Dispõe sobre a tipificação criminal de delitos informáticos; altera o Decreto-Lei $n$ - 2.848, de 7 de dezembro de 1.940 - Código Penal; e dá outras providências. Disponível em:

http://www.planalto.gov.br/ccivil_03/_ato2011-2014/2012/lei/l12737.htm Acesso em: 12 de mai. 2020.

. Lei oㅜ 13.772, de 19 de dezembro de 2018. Altera a Lei no 11.340, de 7 de agosto de 2006 (Lei Maria da Penha), e o Decreto-Lei no 2.848, de 7 de dezembro de 1.940 (Código Penal), para reconhecer que a violação da intimidade da mulher configura violência doméstica e familiar e para criminalizar o registro não autorizado de conteúdo com cena de nudez ou ato sexual ou libidinoso de caráter íntimo e privado. Acesso em: http://www.planalto.gov.br/ccivil_03/_Ato20152018/2018/Lei/L13772.htm. Disponível em: 12 de mai. 2020.

. Lei $\mathrm{n}^{\circ} 11.340$, de 7 de agosto de 2006. Cria mecanismos para coibir a violência doméstica e familiar contra a mulher, nos termos do § 8 do art. 226 da Constituição Federal, da Convenção sobre a Eliminação de Todas as Formas de 
Discriminação contra as Mulheres e da Convenção Interamericana para Prevenir, Punir e Erradicar a Violência contra a Mulher; dispõe sobre a criação dos Juizados de Violência Doméstica e Familiar contra a Mulher; altera o Código de Processo Penal, o Código Penal e a Lei de Execução Penal; e dá outras providências. Acesso em: http://www.planalto.gov.br/ccivil_03/_ato20042006/2006/lei/l11340.htm. Disponível em: 12 de mai. 2020.

CORRÊA, Edna Vitoreti. A aplicabilidade da justiça restaurativa aos casos de pornografia de vingança: um olhar às necessidades das vítimas. Monografia (Graduação de Direito) - Universidade do Sul de Santa Catarina, Tubarão, 2019.

DANCE, Gabriel JX et al. As Facebook Raides a Privacy Wall, It Carved an Openninf for Tech Gian. New York Times. dez. 2018. Disponível em: https://www.nytimes.com/2018/12/18/technology/facebook-privacy.html?auth=linkdismiss-google1tap Acesso em: 20 jan. 2020.

DOMINGUES, Diego Sígoli. Pornografia de vingança e a tutela dos direitos fundamentais da vítima. Dissertação (Mestrado em Direito) - Faculdade Universidade Nove de Julho, São Paulo, 2019.

FLACH, Roberta Matassoli Duran and DESLANDES, Suely Ferreira. Cyber dating abuse or proof of love? The use of apps for surveillance and control in affective-sexual relations. Cad. Saúde Pública [online]. 2019, vol.35, n.1, e00060118. Epub Jan 21, 2019. ISSN 0102-311X. Disponível em: http://dx.doi.org/10.1590/0102-311x00060118. Acesso em: 13 fev. 2020.

FILHO, Tomasevicius, E. (2016). Marco Civil da Internet: uma lei sem conteúdo normativo. Estudos Avançados, 30(86), 269-285. Disponível em: http://www.revistas.usp.br/eav/article/view/115093. Acesso em: 21 jan. 2020.

FIORI, Kauane; ZAGANELLI, Margareth Vetis. Pornografia de vigança: violência de gênero na internet e tutela da intimidade sexual - Um estudo comparado (Itália e Brasil). Derecho y Cambio Social [online]. 2019, v.1 n.59 p. 1-19, jan. 2020.

GUIMARÃES, Ana Larissa Gonçalves. Crimes virtuais e novas modalidades de violência de gênero contra a mulher: a divulgação não consentida de imagens íntimas na internet. 2019. Monografia (Graduação em Direito) - Universidade Federal do Ceará. Fortaleza, 2019.

GONÇALVES, V. H. P. Marco Civil da Internet Comentado. São Paulo - SP: Atlas, 2017. 
GROSS, Daiane. Privacidade na era digital: a intimidade na rede e a suposta misoginia na interpretação dos magistrados. Monografia (Graduação de Direito) Universidade do Vale do Taquari, Lajeado, 2019

LAKATOS, Eva Maria; MARCONI, Marina de Andrade. Fundamentos de metodologia científica. 5. ed. São Paulo: Atlas, 2003.

LOPES, Raíssa de Almeida. A violência de gênero da pornografia de vingança em aplicativos de mensagens instantâneas:

Uma análise jurisprudencial do Superior Tribunal de Justiça. Artigo TCC (Graduação Direito) - Faculdade de Ciências Jurídicas e Sociais - FAJS do Centro Universitário de Brasília (UniCEUB). DF, Brasília, 2019.

LOTT, Diana. Relembre os principais vazamentos de dados de brasileiros em 2018. Folha de São Paulo. São Paulo. jan. 2020. Disponível em: https://www1.folha.uol.com.br/tec/2019/01/relembre-os-principais-vazamentos-dedados-de-brasileiros-em-2018.shtml. Acesso em: 20 jan. 2020

MARRA, Fabiane Barbosa. Desafios do direito na era da internet: Uma breve análise sobre os crimes cibernéticos. Revista Campo Jurídico. Barreira-BA, v.7 n.2, p145-167, julho-dezembro, 2019

MARTINS, Geiza. O que é o Marco Civil da Internet?. Superinteressante, 2015. Seção Mundo Estranho, Tecnologia. Disponível em: https://super.abril.com.br/mundoestranho/o-que-e-o-marco-civil-da-internet/. Acesso em: 21 jan. 2020.

MENESES, Sâmya Pereira. Crimes virtuais: possibilidades e limites da sua regulamentação no brasil. Artigo TCC (Graduação de Direito) - Centro Universitário Fametro - UNIFAMETRO, Fortaleza, 2019.

NOVAIS, Joyce Lobato; CANTUARIA, Isadora. Responsabilidade penal do agente diante da pornografia não consensual perante os crimes cibernéticos contra a mulher no ordenamento jurídico brasileiro. v. 1 n. 1: REVISTA CIENTÍFICA MULTIDISCIPLINAR DO CEAP. Amapá: 2019.

OLIVEIRA, Julia Pereira de. Pornografia de vingança e a indenização no direito civil brasileiro. Trabalho de Conclusão de Curso (Graduação de Direito) - Universidade do Sul de Santa Catarina, Florianópolis, 2019.

QUIVY, R.; CAMPENHOUDT, L. V. Manuel de recherche en sciences sociales. Paris: Dunod, 1995. 
ROCHA, Glauco Capper da; SOUZA FILHO, Veridiano Barroso. Da guerra às emoções: história da internet e o controverso surgimento do Facebook. in: IV Encontro Regional Norte de História da Mídia. Rio Branco. Anais eletrônicos[...] Recife: ALCAR, 2016, Disponível em: http://www.ufrgs.br/alcar/encontros-nacionais1/encontros-regionais/norte/4o-encontro-2016/gt-historia-da-midia-digital/da-guerra-asemocoes-historia-da-internet-e-o-controverso-surgimento-do-facebook/view Acesso em: 20 jan. 2020

SEGATO, Maria Segato. Biopoder e desigualdade de gênero: A sujeição do corpo feminino. Monografia (Graduação de Direito). CENTRO UNIVERSITÁRIO ANTÔNIO EUFRÁSIO DE TOLEDO DE PRESIDENTE PRUDENTE. São Paulo. Presidente Prudente. 2019.

SEVERINO, Antônio Joaquim. Metodologia do Trabalho Científico. $23^{\circ}$ Ed. Revisada e atualizada. São Paulo: Cortez, 2017.

MARQUES, A.S.S.; MARQUES, J.W.P. Responsabilidade civil e penal pelo dano à honra, à imagem e à intimidade das vítimas de pornografia de vingança. 2015. 63 f. Monografia (Graduação em Direito) - Faculdade de Direito, Universidade Federal do Ceará, Fortaleza, 2015.

VARELLA, Gabriela; SOPRANA, Paula. Pornografia de vingança: crime rápido, trauma permanente. Época, 2016. Disponível em:

http://epoca.globo.com/vida/experienciasdigitais/noticia/2016/02/pornografia-devinganca-crime-rapido-trauma-permanentee.html. Acesso em 14 de janeiro de 201 